\title{
DIVULGAÇÃO DE PESQUISA: obrigatoriedade do voto e determinantes sociais ${ }^{*}$
}

\author{
Luzia Helena Hermann de Oliveira ${ }^{1}$ \\ Marcolina N. Tomazini de Carvalho ${ }^{2}$
}

\author{
'Professora do Depto. de Ciências Sociais da Universidade Estadual de Londrina; \\ Doutora em Ciências Políticas pela Pontifícia Universidade Católica de São Paulo. \\ ${ }^{2}$ Professora do Depto. de Ciências Sociais da Universidade Estadual de Londrina.
}

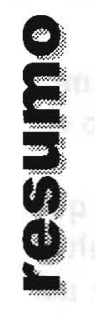

\begin{abstract}
Trata-se de uma pesquisa de opinião que procura determinar como a população do município de Londrina, no Paraná, encara a possibilidade de implantação do voto facultativo, que procedimento adotaria em semelhante situação e qual o motivo que nortearia tal procedimento. O objetivo do projeto é verificar, primeiro, se as pessoas favoráveis ao voto facultativo podem ser social ou politicamente caracterizadas e, segundo, em que medida a implantação do voto facultativo atingiria diferentemente os vários segmentos sociais.
\end{abstract}

Palavras-chave: eleições; voto facultativo; participação.

$\mathbf{T}$ rata-se de uma pesquisa de opinião que procura determinar como a população do município de Londrina, no Paraná, encara a possibilidade de implantação do voto facultativo, que procedimento adotaria em semelhante situação e qual o motivo que nortearia tal procedimento. O objetivo do projeto é verificar, primeiro, se as pessoas favoráveis ao voto facultativo podem ser social ou politicamente caracterizadas e, segundo, em que medida a implantação do voto facultativo atingiria diferentemente os vários segmentos sociais.

Para tal, foi realizada uma pesquisa aleatória na área urbana de Londrina durante os meses de abril e maio de 1997, aplicando-se um questionário a 700 entrevistados, todos maiores de 18 anos. A amostra foi probabilística, estratificada segundo os padrões de moradia, efetuando-se um sorteio aleatório dos setores censitários e aplicando-se quotas proporcionais ao sexo e à atividade econômica (economicamente ativos e não-ativos). Nesse processo, a margem de erro considerada é de aproximadamente $5 \%$, dentro do intervalo de confiança de $95 \%$.

Este artigo tem por finalidade encerrar a primeira etapa do desenvolvimento do projeto, apresentando os resultados da pesquisa. ${ }^{1}$

\section{O VOTO DEVE SER OBRIGATÓRIO?}

\begin{tabular}{lcr}
\hline OPINIÕES & N $^{\circ}$ ABSOLUTO & $\%$ \\
\hline Obrigatório & 209 & 29,9 \\
Facultativo & 479 & 68,4 \\
NS/NR ${ }^{(*)}$ & 12 & 1,7 \\
\hline TOTAL & $\mathbf{7 0 0}$ & $\mathbf{1 0 0 , 0}$ \\
\hline
\end{tabular}

(") Não sabem/não responderam.

O percentual das pessoas favoráveis ao voto facultativo é de $68,4 \%$, contra $29,9 \%$ que preferem o voto obrigatório. Esse percentual está bastante próximo ao encontrado em pesquisas de opinião recentemente realizadas em outras regiões do Brasil. ${ }^{2}$ 
1.1.Relação entre opinião sobre a obrigatoriedade do voto e características socioeconômicas dos entrevistados (em \%):

\begin{tabular}{lcc}
\hline \multirow{2}{*}{ OPINIÕES } & M & FEXO \\
\hline Obrigatório & 24,1 & 36,5 \\
Facultativo & 75,9 & 63,5 \\
\hline No Abs. $^{*}$ * & $\mathbf{3 4 0}$ & $\mathbf{3 4 8}$
\end{tabular}

"Foram excluídos 12 entrevistados (1,7\% do total de 700) que não declararam opinião (NS/NR).

\begin{tabular}{lcccc}
\hline \multirow{2}{*}{ OPINIÕES } & \multicolumn{5}{c}{ IDADE } \\
& $18-25$ anos & $26-40$ anos & $41-60$ anos & + de 61 anos \\
\hline Obrigatório & 37,2 & 25,9 & 29,7 & 33,3 \\
Facultativo & 62,8 & 74,1 & 70,3 & 66,7 \\
\hline No Abs. $^{*}$ & $\mathbf{1 3 7}$ & $\mathbf{2 4 3}$ & $\mathbf{2 1 2}$ & $\mathbf{9 6}$ \\
\hline
\end{tabular}

(") Foram excluídos 12 entrevistados $(1,7 \%$ do total de 700$)$ que não declararam opinião (NS/NR).

Inserção no mercado de trabalho

\begin{tabular}{lcc}
\hline OPINIÕES & Trabalham & Não Trabalham \\
\hline Obrigatório & 28,4 & 33,2 \\
Facultativo & 71,6 & 66,7 \\
\hline $\mathbf{N}^{\circ}$ Abs. ${ }^{(*)}$ & $\mathbf{4 0 8}$ & $\mathbf{2 8 0}$ \\
\hline
\end{tabular}

(") Foram excluídos 12 entrevistados (1,7\% do total de 700$)$ que não declararam opinião (NS/NR)

\section{Renda familiar (em salários mínimos)}

\begin{tabular}{lrrrrrr}
\hline OPINIÕES & até $2 \mathrm{sm}$ & $\begin{array}{c}+ \text { de } 2 \\
\text { até } 5 \mathrm{sm}\end{array}$ & $\begin{array}{c}+ \text { de } 5 \\
\text { até } 10 \mathrm{sm}\end{array}$ & $\begin{array}{r}+ \text { de } 10 \\
\text { até } 20 \mathrm{sm}\end{array}$ & + de 20sm \\
\hline Obrigatório & 34,8 & 33,9 & 31,4 & 24,1 & 20,9 \\
Facultativo & 65,2 & 66,1 & 68,6 & 75,9 & 79,1 \\
\hline $\mathbf{N}^{\circ}$ Abs.(*) & $\mathbf{8 9}$ & $\mathbf{2 1 8}$ & $\mathbf{1 8 8}$ & $\mathbf{1 0 8}$ & $\mathbf{6 7}$ \\
\hline
\end{tabular}

") Foram excluídos 30 entrevistados (9,6\% do total de 700), sendo 18 que não declararam renda e 12 que não emitiram opinião (NS/NR).

\section{Nivel de escolaridade}

\begin{tabular}{lcccc}
\hline OPINIÕES & $\begin{array}{c}\text { Primário } \\
\text { Incompleto }\end{array}$ & $\begin{array}{c}1^{\circ} \text { Grau } \\
\text { Completo }\end{array}$ & $\begin{array}{c}\text { Colegial } \\
\text { Completo }\end{array}$ & Universitário \\
\hline Obrigatório & 33,8 & 30,5 & 27,9 & 15,3 \\
Facultativo & 66,2 & 69,5 & 72,1 & 84,7 \\
\hline $\mathbf{N}^{0}$ Abs. $\left.{ }^{*}\right)$ & $\mathbf{3 6 1}$ & $\mathbf{1 2 8}$ & $\mathbf{1 4 0}$ & $\mathbf{5 9}$ \\
\hline
\end{tabular}

(") Foram excluídos 12 entrevistados (1,7\% do total de 700$)$ que não declararam opinião (NS/NR).

$O$ voto facultativo é preferido em todos os subagrupamentos sociais (segundo sexo, idade, inserção no mercado de trabalho, renda familiar e escolaridade). Analisando-se os percentuais relativos à preferência pelo voto obrigatorio, verifica-se que a tendência mais acentuada está entre as mulheres e entre os mais jovens (18-25 anos) e os mais velhos (mais de 61 anos).
Observa-se, ainda, a interferência das variáveis renda e escolaridade na opinião, existindo uma relação diretamente proporcional entre renda, nível de escolaridade e preferência pelo voto facultativo.

\subsection{Relação entre a opinião sobre a obrigatoriedade do voto e perfil político- ideológico dos entrevistados (em \%):}

ldeologio(*)

\begin{tabular}{lcccc}
\hline OPINIÕES & Direita & Centro & Esquerda & Não Sabem \\
\hline Obrigatório & 30,7 & 22,1 & 31,5 & 42,1 \\
Facultativo & 69,3 & 77,9 & 68,5 & 57,9 \\
\hline $\mathbf{N}^{\circ}$ Abs. ${ }^{(*)}$ & $\mathbf{1 3 7}$ & $\mathbf{8 6}$ & $\mathbf{4 4 5}$ & $\mathbf{1 9}$
\end{tabular}

"Foi perguntado: "Concorda que o governo deve cuidar apenas da segurança pública e da educação, deixando para os empresários os outros setores (saúde, habitação, estradas...)?"

(*)Foram excluídos 13 entrevistados (1,8\% do total de 700 ), sendo que 12 não declararam opinião sobre a obrigatoriedade do voto e 1 não respondeu à questão sobre ideologia.

Esquerda e direita apresentam o mesmo índice de preferência, em torno de $69 \%$ em favor do voto facultativo. É o centro ideológico - aqueles que defendem uma interferência limitada do Estado - que tende mais enfaticamente a defender o voto facultativo $(77,9 \%)$. Inversamente, o pequeno percentual que não tem opinião formada sobre o nível ideal de intervenção do Estado (dezenove entrevistados em 700 , ou seja, $2,7 \%$ do total) mantém a preferência pelo voto facultativo em percentual bem mais baixo $(57,9 \%)$.

\section{Apoio à democracia*}

\begin{tabular}{lccc}
\hline OPINIŌES & Democratas & Autoritários & Não Sabem/Indiferentes \\
\hline Obrigatório & 29,7 & 27,0 & 44,2 \\
Facultativo & 70,3 & 73,0 & 55,7 \\
\hline $\mathbf{N}^{*}$ Abs. ${ }^{(*)}$ & $\mathbf{5 3 5}$ & $\mathbf{1 0 0}$ & $\mathbf{5 2}$ \\
\hline
\end{tabular}

(*) Foi perguntado: "Na sua opinião, é importante para o país manter a liberdade democrática de voto, opinião e associação ou acha que, em determinadas situações, o governo não pode ser democrático?"

(•) Foram excluídos 13 entrevistados (1,8\% do total de 700), sendo 12 que não declararam opinião (NS/NR) sobre a obrigatoriedade do voto e 1 que não respondeu à questão sobre a intervenção do Estado.

Também em relação ao apoio à democracia não aparecem diferenças significativas, pois tanto autoritários quanto democratas preferiram o voto obrigatório e o voto facultativo em percentuais muito próximos. O que se distingue na tabela é o percentual de entrevistados que não souberam dizer qual o regime político de sua preferência ou que demonstraram indiferença em relação aos dois regimes. Nesse caso, a preferência pelo voto obrigatório foi maior, mas esse grupo é pequeno (52 entrevistados em 700 , ou seja, $7,8 \%$ do total). 
1.3. Relação entre a opinião sobre a obrigatoriedade do voto e grau de interesse pela política (em \%):

Interesse pelo noticiário político ${ }^{*}$

\begin{tabular}{|c|c|c|c|}
\hline OPINIÕES & Sempre & Às Vezes & Nunca \\
\hline Obrigatório & 26,1 & 34,2 & 30,6 \\
\hline Facultativo & 73,9 & 65,8 & 69,4 \\
\hline $\mathbf{N}^{0}$ Abs.(*) & 280 & 269 & 134 \\
\hline
\end{tabular}

Interesse pelo debate político ${ }^{*}$

\begin{tabular}{|c|c|c|c|}
\hline OPINIÕES & Sempre & Às Vezes & Nunca \\
\hline Obrigatório & 17,7 & 31,8 & 33,6 \\
\hline Facultativo & 82,3 & 68,2 & 66,4 \\
\hline $\mathbf{N}^{\circ}$ Abs..$^{(*)}$ & 124 & 198 & 363 \\
\hline
\end{tabular}

O interesse pela política foi medido de duas formas: entre os entrevistados que se interessam pelo noticiário político e entre os entrevistados que debatem sobre política com amigos e parentes. Partiu-se do pressuposto de que discutir política é uma maneira mais precisa de demonstrar interesse do que meramente assistir ao noticiário.

Vê-se que a preferência pelo voto facultativo prevaleceu em todas as situações. Na tabela referente ao noticiário político, observa-se que entre os que vêem ou lêem sempre os noticiários a preferência pelo voto facultativo é maior. Essa vantagem em favor do voto facultativo cresce substancialmente quando o fator analisado passa a ser o debate político. Entre os que debatem sempre, ou seja, entre os segmentos mais interessados (uma minoria de $17,7 \%$ 124 entrevistados em 700), a preferência pelo voto facultativo aparece em 82,3\% dos casos.

\section{Preferência partidária}

\begin{tabular}{|c|c|c|}
\hline OPINIÕES & Têm Preferência & Não Têm Preferência \\
\hline Obrigatório & 42,7 & 28,2 \\
\hline Facultativo & 57,3 & 71,8 \\
\hline $\mathbf{N}^{\circ} \mathbf{A b s} .^{(*)}$ & 103 & 585 \\
\hline
\end{tabular}

\section{Participação em associações}

\begin{tabular}{|c|c|c|}
\hline OPINIÕES & Participa & Não Participa \\
\hline Obrigatório & 36,3 & 28,2 \\
\hline Facultativo & 63,7 & 71,8 \\
\hline $\mathbf{N}^{o}$ Abs..$^{(*)}$ & 171 & 510 \\
\hline
\end{tabular}

Diferentemente das duas questões anteriores, a simpatia por partidos políticos e a participação em associações parecem influenciar a opinião, aumentando o percentual dos que apoiam o voto obrigatório. Embora também neste caso a preferência pelo voto facultativo prevaleça em todas as situações (sempre em mais de $50 \%$ ), o percentual de apoio é mais baixo entre os que demonstram preferência partidária ou participam de associações. Portanto, há uma inversão em relação às duas perguntas anteriores.

\subsection{0 voło deve ser obrigatório? Por que?}

Com o objetivo de compreender os motivos dessa preferência, foi formulada uma pergunta aberta, possibilitando que o entrevistado desse espontaneamente sua opinião. A sistematização foi feita posteriormente, procurando-se respeitar o sentido da resposta. ${ }^{3}$

Para um percentual expressivo dos entrevistados $(35,9 \%)$ o voto deve ser facultativo, porque votar é um direito de cidadania. Ainda favoráveis ao voto facultativo, encontrase o percentual bem menor $(9,1 \%)$ dos que acreditam que a implantação do voto facultativo retiraria do processo eleitoral os desinteressados e mal informados que, segundo eles, apenas contribuem para piorar a qualidade da política. Para $8 \%$, a justificativa para implantar o voto facultativo está na ineficiência do voto obrigatório, uma vez que os desinteressados podem anular seu voto e manter, assim, uma forma de não-participação. Somente 5,1\% dos que preferiram o voto facultativo demonstraram claro desapreço pela política, utilizando sempre formas pejorativas para se referir à política $\mathrm{e}$ aos políticos.

\begin{tabular}{clrr}
\hline SIM/NÃO & MOTIVOS & N $^{\circ}$ ABS. & $\%$ \\
\hline SIM & -Sem a obrigatoriedade & & \\
& poucos votariam & 108 & 15,4 \\
& -Votar é um dever cívico & 30 & 4,3 \\
& -Uma forma de constituir & & \\
& governos & 21 & 3,0 \\
& -Para criar o interesse político & & \\
& na maioria do povo & 9 & 1,3 \\
& -Outros/NS/NR & 40 & 5,9 \\
NÃO & -Votar é um direito & 251 & 35,9 \\
& -O voto facultativo melhoraria & & \\
& a qualidade da política & 64 & 9,1 \\
& -A obrigação não garante o & & \\
& voto e a participação & 56 & 8,0 \\
& -Os políticos não prestam & 36 & 5,1 \\
& -Outros/NS/NR & 73 & 10,4 \\
\hline TOTAL & & $\mathbf{6 8 8}$ & $\mathbf{1 0 0 , 0}$ \\
\hline
\end{tabular}

(") Foram excluídos 12 entrevistados (1,7\% do total de 700$)$ que não declararam opinião (NS/NR).

Quanto à preferência pelo voto obrigatório, um percentual expressivo $(15,4 \%)$ reafirmou a antiga convicção de que sem a obrigatoriedade poucos votariam. Em seguida, com um percentual bem mais baixo $(4,3 \%)$, aparece a parcela 
dos que afirmam que votar é um dever. A noção schumpeteriana de que eleição é uma forma de se constituir governos foi repetida por $3 \%$ dos entrevistados. $\mathrm{E}$ apenas $1,3 \%$ disseram que as eleições servem para politizar a população, ensinando o povo a participar da política.

\section{VOTARIA SE O VOTO NÃO FOSSE OBRIGATÓRIO?}

\begin{tabular}{lcr}
\hline OPINIÕES & No ABS $^{\circ}$ & $\%$ \\
\hline Votaria & 368 & 52,6 \\
Depende & 150 & 21,4 \\
Não Votaria & 167 & 23,9 \\
NS/NR & 15 & 2,1 \\
\hline $\mathbf{N}^{\circ}$ Abs. & $\mathbf{7 0 0}$ & $\mathbf{1 0 0 , 0}$ \\
\hline
\end{tabular}

A maioria votaria mesmo que não fosse obrigada, mas o número dos que não votariam é também bastante expressivo $(23,9 \%)$, e um percentual de $21,9 \%$ votaria sob determinadas condições. Vê-se, portanto, que o percentual dos que participariam com certeza é de cerca de metade da população em idade de participar, o que demonstra um alto índice de desapego ao processo eleitoral. Comparando-se esses dados aos resultados apresentados por MOISÉS (1995), vê-se que essa determinação costuma variar segundo a conjuntura política. Em 1989, quando pela primeira vez, depois de quase três décadas, a população novamente pôde votar para escolher o presidente da República, a tendência em participar cresceu. Mas em 1993, quando o presidente eleito já havia sofrido o processo de impeachment, esse percentual caiu em mais de dez pontos percentuais. ${ }^{4}$ Em Londrina, o número dos que votariam está bastante próximo ao percentual da pesquisa de 1993. Comparando esses dados, vê-se que o número dos que talvez votassem foi muito baixo nas quatro pesquisas apresentadas por Moisés (em torno de 3\%). Em Londrina, pelo contrário, um considerável percentual de $21,4 \%$ preferiu o "depende".

\subsection{Relação entre a disposição dos entrevistados em participar do processo eleitoral e suas características socio- econômicas (em \%):}

\begin{tabular}{lrc}
\hline \multirow{2}{*}{ OPINIÕES } & M & SEXO \\
& 54,9 & 52,6 \\
\hline Votaria & 22,7 & 21,1 \\
Depende & 22,4 & 26,3 \\
Não Votaria & $\mathbf{3 3 9}$ & $\mathbf{3 4 6}$
\end{tabular}

". Foram excluídos 15 entrevistados (2,1\% do total de 700$)$ que não declararam opinião (NS/NR).

\begin{tabular}{|c|c|c|c|c|}
\hline OPINIÕES & $18-25$ anos & $\begin{array}{l}\text { IDAI } \\
26-40 \text { anos }\end{array}$ & $\begin{array}{l}\mathrm{DE} \\
41-60 \text { anos }\end{array}$ & + de 61 anos \\
\hline Votaria & 51,8 & 54,0 & 53,1 & 57,3 \\
\hline Depende & 21,9 & 26,4 & 19,7 & 15,6 \\
\hline Não Votaria & 26,3 & 19,7 & 27,2 & 27,1 \\
\hline $\mathbf{N}^{0} \mathbf{A b s} .^{(*)}$ & 137 & 239 & 213 & 96 \\
\hline
\end{tabular}

Inserção no mercado de trabalho

\begin{tabular}{lcc}
\hline OPINIÕES & Trabalham & Não Trabalham \\
\hline Votaria & 54,1 & 53,2 \\
Depende & 23,0 & 20,4 \\
Não Votaria & 23,0 & 26,4 \\
\hline No Abs. $^{(*)}$ & $\mathbf{4 0 5}$ & $\mathbf{2 8 0}$ \\
\hline
\end{tabular}

(") Foram excluídos 15 entrevistados (2,1\% do total de 700$)$ que não declararam opinião (NS/NR).

\section{Renda familiar (em salários mínimos)}

\begin{tabular}{lrcccr}
\hline OPINIÕES & até 2 sm & $\begin{array}{c}+ \text { de } 2 \\
\text { até } 5 \mathrm{sm}\end{array}$ & $\begin{array}{c}+ \text { de } 5 \\
\text { até } 10 \mathrm{sm}\end{array}$ & $\begin{array}{c}+ \text { de } 10 \\
\text { até } 20 \mathrm{sm}\end{array}$ & + de 20sm \\
\hline Votaria & 50,6 & 50,7 & 51,6 & 56,6 & 64,2 \\
Depende & 17,2 & 20,1 & 24,5 & 28,3 & 20,9 \\
Não votaria & 32,2 & 29,2 & 23,9 & 15,1 & 14,9 \\
\hline $\mathbf{N}^{\circ}$ Abs. ${ }^{(*)}$ & $\mathbf{8 7}$ & $\mathbf{2 1 9}$ & $\mathbf{1 8 8}$ & $\mathbf{1 0 6}$ & $\mathbf{6 7}$ \\
\hline
\end{tabular}

(") Foram excluídos 33 entrevistados (4,7\% do total de 700$)$, sendo 15 que não declararam opinião (NS/NR) e 18 que não declararam renda.

\section{Nível de escolaridade}

\begin{tabular}{lcccc}
\hline OPINIÕES & $\begin{array}{c}\text { Primário } \\
\text { Incompleto }\end{array}$ & $\begin{array}{c}1^{\circ} \text { Grau } \\
\text { Completo }\end{array}$ & $\begin{array}{c}\text { Colegial } \\
\text { Completo }\end{array}$ & Universitário \\
\hline Votaria & 48,5 & 51,6 & 62,6 & 69,5 \\
Depende & 20,4 & 23,4 & 23,0 & 25,4 \\
Não Votaria & 31,1 & 25,0 & 14,4 & 5,1 \\
\hline No Abs. $^{(*)}$ & $\mathbf{3 6 3}$ & $\mathbf{1 2 4}$ & $\mathbf{1 3 9}$ & $\mathbf{5 9}$
\end{tabular}

(") Foram excluídos 15 entrevistados (2,1\% do total de 700) que não declararam opinião (NS/NR).

Apesar de algumas diferenças percentuais, não aparecem divergências significativas na opinião manifestada entre diferentes sexos, idades ou pessoas economicamente ativas e não-ativas. Das variáveis socioeconômicas apresentadas, a renda familiar e a educação são, claramente, os fatores mais expressivos. Como se pode observar, o número dos que votariam cresce com o crescimento da renda (em até quatorze pontos percentuais) e, entre os que recebem até dois salários mínimos, a disposição em não votar é 17,3\% maior que entre os de renda acima de vinte salários mínimos.

O mesmo padrão se repete em relação ao grau de escolaridade: quanto maior a escolaridade, maior a intenção de participar. Entre as pessoas com nível universitário, a tendência à abstenção é de apenas $5,1 \%$. 
2.2.Relação entre disposição em participar do processo eleitoral e perfil políticoideológico dos entrevistados (em \%):

Ideologia")

\begin{tabular}{lcccc}
\hline OPINIÕES & Direita & Centro & Esquerda & Não Sabem \\
\hline Votaria & 55,1 & 58,1 & 53,0 & 38,9 \\
Depende & 24,6 & 26,7 & 20,3 & 16,7 \\
Não Votaria & 20,3 & 15,1 & 26,6 & 44,4 \\
\hline N $^{*}$ Abs. ${ }^{(*)}$ & $\mathbf{1 3 8}$ & $\mathbf{8 6}$ & $\mathbf{4 4 3}$ & $\mathbf{1 8}$
\end{tabular}

(") Foi perguntado: "Concorda que o governo deve cuidar apenas da segurança pública e da educação, deixando para os empresários os outros setores (saúde, habitação, estradas...)?"

(**) Foram excluídos 15 entrevistados $(2,1 \%$ do total de 700$)$ que não declararam opinião (NS/NR).

Esquerda, centro e direita apresentam comportamentos semelhantes, embora entre os adeptos da esquerda apareça um número proporcionalmente maior de pessoas que não votariam. Encontra-se no centro ideológico o menor percentual dos que não votariam. Contudo, o grupo que efetivamente chama a atenção na tabela é aquele que não tem opinião formada sobre o grau desejável de intervenção do Estado (dezoito entrevistados). Neste caso, os que votariam formam a minoria.

\section{Apoio à democracio(*)}

\begin{tabular}{lccc}
\hline OPINIÕES & Democratas & Autoritários & Não Sabem/Indiferentes \\
\hline Votaria & 56,4 & 52,5 & 30,8 \\
Depende & 21,1 & 23,2 & 26,9 \\
Não Votaria & 22,4 & 24,2 & 42,3 \\
\hline No $^{\circ}$ Abs. ${ }^{(* *)}$ & $\mathbf{5 3 2}$ & $\mathbf{9 9}$ & $\mathbf{5 2}$ \\
\hline ") Foi perguntado: "Na sua opinião, é importante para o país manter a \\
liberdade democrática de voto, opinião e associação ou acha que, em \\
determinadas situações, o governo não pode ser democrático?" \\
(*o) Foram excluídos 17 entrevistados (2,4\% do total de 700), sendo 15 que \\
não declararam opinião (NS/NR) sobre a obrigatoriedade do voto e 2 \\
que não responderam sobre a intervenção do Estado.
\end{tabular}

Aqui o padrão se repete. Embora seja possível afirmar que os democratas apresentam uma disposição maior em participar, o comportamento de autoritários e democratas assemelha-se, uma vez que ambos afirmam (em percentuais bastante próximos) que votariam. A nítida variação encontrase entre os que responderam que lhes é indiferente ou que não sabem dizer qual o melhor regime político: em maioria, esse grupo afirma que não votaria se o voto fosse facultativo. Entre indiferentes e NS/NR, estão 52 entrevistados, ou seja, $7,4 \%$ do total.
Grau de otimismo em relação ao país - $l^{*}{ }^{*}$

\begin{tabular}{lccc}
\hline OPINIÕES & Ruim/Péssima & Regular & Boa/Ótima \\
\hline Votaria & 49,0 & 57,9 & 58,3 \\
Depende & 20,7 & 23,3 & 20,9 \\
Não Votaria & 30,3 & 18,8 & 20,9 \\
\hline $\mathbf{N}^{\circ}$ Abs.(**) & $\mathbf{2 9 4}$ & $\mathbf{2 6 6}$ & $\mathbf{1 1 5}$
\end{tabular}

" Foi perguntado: "Em sua opinião, como está a situação do Brasil atual?"

(*)Foram excluídos 25 entrevistados (3,5\% do total de 700$)$ que não declararam opinião.

\section{Grau de otimismo em relação ao país - $\|^{(*)}$}

\begin{tabular}{lccc}
\hline OPINIÕES & Piorou & Continua Igual & Melhorou \\
\hline Votaria & 48,8 & 49,7 & 59,0 \\
Depende & 20,9 & 23,5 & 21,6 \\
Não Votaria & 30,3 & 26,8 & 19,4 \\
\hline No Abs. $^{(*)}$ & $\mathbf{2 0 1}$ & $\mathbf{1 5 3}$ & $\mathbf{3 2 4}$
\end{tabular}

"Foi perguntado: "Comparando com os anos anteriores, o Brasil melhorou, continua igual ou piorou?"

(") Foram excluídos 22 entrevistados (3,1\% do total de 700$)$ que não declararam opinião.

Embora os otimistas apresentem, como seria de se esperar, uma tendência maior em participar, nota-se que também os pessimistas, em maioria, afirmam a intenção de participar do processo eleitoral. Nas duas tabelas, a diferença percentual entre otimistas e pessimistas é de cerca de $10 \%$, numa relação diretamente proporcional entre otimismo e interesse em participar. Na primeira tabela, os que preferiram o intermediário "regular" estão mais próximos dos otimistas (é o menor índice de "não votaria"). Na segunda tabela, diferentemente, os que preferiram o intermediário "a situação permanece igual" estão mais próximos dos pessimistas.

\subsection{Relação entre a disposição em participar das eleições e grau de interesse pela política (em \%):}

Interesse pelo noticiário político(*)

\begin{tabular}{lccc}
\hline OPINIÕES & Sempre & Às Vezes & Nunca \\
\hline Votaria & 60,8 & 57,4 & 31,9 \\
Depende & 22,0 & 22,1 & 22,2 \\
Não Votaria & 17,2 & 20,6 & 45,9 \\
\hline $\mathbf{N}^{\circ}$ Abs. ${ }^{* *}$ & $\mathbf{2 7 3}$ & $\mathbf{2 7 2}$ & $\mathbf{1 3 5}$ \\
\hline
\end{tabular}

(") Foi perguntado: "Costuma ver ou ler noticiários políticos?"

(•) Foram excluídos 20 entrevistados (2,8\% do total de 700$)$ que não declararam opinião (NS/NR). 
Interesse pelo debate politico ${ }^{*}$ ]

\begin{tabular}{lccc}
\hline OPINIÕES & Sempre & Às Vezes & Nunca \\
\hline Votaria & 69,7 & 61,4 & 44,4 \\
Depende & 19,7 & 24,4 & 21,5 \\
Não Votaria & 10,7 & 14,2 & 34,2 \\
\hline $\mathbf{N}^{\circ}$ Abs. ${ }^{* *}$ & $\mathbf{1 2 2}$ & $\mathbf{1 9 7}$ & $\mathbf{3 6 3}$ \\
\hline
\end{tabular}

" Foi perguntado: "Costuma discutir política com amigos e parentes?"

(*) Foram excluídos 18 entrevistados (2,5\% do total de 700$)$ que não declararam opinião (NS/NR).

O interesse pela política é um fator relevante na disposição do eleitor em participar. Entre os que sempre lêem ou vêem os noticiários, mais de $60 \%$ votariam com certeza, contra $17,2 \%$ que não votariam. Entre os que nunca assistem aos noticiários políticos, a maior parte respondeu que não votaria.

Nota-se também que interessar-se pelo noticiário é algo bem mais corriqueiro do que debater sobre política: 363 pessoas responderam que nunca discutem política, contra 135 que nunca vêem ou lêem os noticiários.

Entre os que discutem sempre, cresce o percentual dos que votariam com certeza. Mas também entre os que nunca discutem prevalece a disposição de participar das eleições. Observe-se que esse não é um número desprezível: 161 entrevistados (23\% dentre os 700 ) afirmaram que votariam com certeza, embora nunca discutam sobre política.

Preferência partidária

\begin{tabular}{lcc}
\hline OPINIÕES & Têm Preferência(*) & Não Têm Preferência \\
\hline Votaria & 64,4 & 51,9 \\
Depende & 20,8 & 22,1 \\
Não Votaria & 14,9 & 26,0 \\
\hline No Abs.(*) $^{*}$ & $\mathbf{1 0 1}$ & $\mathbf{5 8 4}$
\end{tabular}

(") Apenas 103 entrevistados declararam possuir preferência partidária. Destes, as preferências foram: PMDB - 32; PT - 32; PSDB -16; PDT 10; PTB/PFL - 5; VÁRIOS - 5; OUTROS - 3

(*) Foram excluídos 15 entrevistados $(2,1 \%$ do total de 700$)$ que não declararam opinião (NS/NR).

\section{Participação em associações}

\begin{tabular}{lcc}
\hline OPINIÕES & Participa & Não participa \\
\hline Votaria & 61,8 & 51,2 \\
Depende & 18,2 & 22,8 \\
Não Votaria & 20,0 & 26,0 \\
\hline $\mathbf{N}^{0}$ Abs.* & $\mathbf{1 7 0}$ & $\mathbf{5 0 8}$ \\
\hline
\end{tabular}

(*) Foram excluídos 22 entrevistados (3,1\% do total de 700) que não declararam opinião (NS/NR).

A preferência partidária e a participação em associações também indicam uma propensão em votar, apresentando diferenças de até $10 \%$.
Votos dados nas eleições de 1994 - / (*) (entre os que votariam com certeza)

\begin{tabular}{|c|c|c|c|c|c|}
\hline $\begin{array}{c}\text { GRAU DE } \\
\text { LEMBRANÇA }\end{array}$ & Presidente & Governador & Senador & $\begin{array}{l}\text { Dep. } \\
\text { Federal }\end{array}$ & $\begin{array}{c}\text { Dep. } \\
\text { Estadual }\end{array}$ \\
\hline Não lembra & 17,3 & 23,1 & 49,9 & 52,3 & 56,7 \\
\hline $\mathrm{NV}^{(* *)} / \mathrm{Nulo} / \mathrm{Branc}$ & 12,9 & 16,1 & 21,8 & 21,9 & 22,6 \\
\hline Soube responder & 69,8 & 60,9 & 28,4 & 25,8 & 20,7 \\
\hline$N^{0}$ Abs. ${ }^{(* * *)}$ & 364 & 360 & 363 & 365 & 363 \\
\hline \multicolumn{6}{|c|}{$\begin{array}{l}\text { Foi perguntado: "Em 1994, em quem votou para presidente da República? } \\
\text { E para governador? E para senador? E para deputado federal? E para } \\
\text { deputado estadual?" }\end{array}$} \\
\hline
\end{tabular}

Votos dados nas eleições de 1994 - $/\left.\right|^{*}$ (entre os que não votariam)

\begin{tabular}{|c|c|c|c|c|c|}
\hline $\begin{array}{c}\text { GRAU DE } \\
\text { LEMBRANÇA }\end{array}$ & Presidente & Governador & Senador & $\begin{array}{c}\text { Dep. } \\
\text { Federal }\end{array}$ & $\begin{array}{l}\text { Dep. } \\
\text { Estadua }\end{array}$ \\
\hline & & & & & \\
\hline o/Branco & 30,9 & & & 43,9 & 45,1 \\
\hline er & 41,3 & & & , J & 9,1 \\
\hline Aows. & & & & 164 & 164 \\
\hline \multicolumn{6}{|c|}{$\begin{array}{l}\text { Foi perguntado: "Em 1994, em quem votou para presidente da República? } \\
\text { E para governador? E para senador? E para deputado federal? E para } \\
\text { deputado estadual?" } \\
\text { (') Não votou. } \\
\text { foram excluídos. }\end{array}$} \\
\hline
\end{tabular}

No que se refere aos cargos em disputa, tanto entre os que votariam quanto entre os que não votariam aparecem grandes diferenças no grau de lembrança. Nas duas tabelas, o nome do candidato a presidente da República foi, de longe, o mais lembrado. Em seguida vem o nome do candidato a governador.

Como seria de se esperar, os percentuais de votos nulos, em branco e de abstenções foram bem mais altos entre os que não votariam. Também esperado, o grau de lembrança, para todos os cargos, foi bem mais alto entre os que votariam.

Contudo, para os cargos legislativos, o grau de lembrança foi muito baixo mesmo entre os que votariam com certeza. Ou seja, para a eleição de senador, deputado federal e deputado estadual, a esmagadora maioria dos entrevistados não conseguiu dizer para quem foi seu voto. Esse fato é claramente observado mesmo entre aqueles que pretendem continuar votando se o voto se tornar facultativo: nesse caso, o índice de lembrança para as cadeiras legislativas é de cerca de $25 \%$. Entre os que não votariam, esses índices sobem de maneira alarmante: mais de $90 \%$ não respondeu para quem foi seu voto.

\subsection{Votaria se não fosse obrigatório? Por que?5}

Como havia três possibilidades de resposta ("votaria", "depende", "não votaria"), as justificativas dos entrevistados estavam ligadas às perguntas, referindo-se a essas possibilidades. Contudo, analisando as respostas, observamos que a tabela poderia ser simplificada, uma vez que o sentido 
das respostas seguiam basicamente duas direções: aquela em que os entrevistados demonstravam tendência em participar (mesmo tendo algumas vezes respondido "depende") e aquela em que pareciam mais propensos a alienar-se do processo (mesmo tendo respondido "depende").

\begin{tabular}{llrr}
\hline TENDÊNCIA & MOTIVOS & N ${ }^{\circ}$ ABS. & $\%$ \\
\hline PARTICIPAR & -Para exercer o direito de & & \\
& participação & 155 & 22,6 \\
& -Pela noção do dever cívico & 115 & 16,8 \\
& -Votaria se o candidato fosse bom & 97 & 14,2 \\
& -Devido ao gosto pela festa & 32 & 4,7 \\
& - Outras/NS/NR & 66 & 9,6 \\
NÃO PARTICIPAR & -Pelo ressentimento com a política & & \\
& e os políticos & 95 & 13,9 \\
& -Não se interessa pela política & 48 & 7,0 \\
& -Outras/NS/NR & 77 & 11,2 \\
\hline TOTAL $(\cdot)$ & & $\mathbf{6 8 5}$ & $\mathbf{1 0 0 , 0}$ \\
\hline
\end{tabular}

"Foram excluídos 15 entrevistados (2,1\% do total de 700) que não responderam ou não souberam responder se votariam ou não.

Entre os que demonstraram disposição em participar das eleições mesmo que o voto seja facultativo, a maior parte $(22,6 \%)$ afirmou que o faria pelo direito de escolher, pelo direito de eleger alguém de sua confiança. Trata-se, portanto, de uma tendência positiva, no sentido de acreditar no processo eleitoral e na capacidade de influência dos eleitores. Outro tipo de resposta desses entrevistados tendentes a participar foi a que denominamos de "noção do dever cívico", e que apareceu em respostas como "votaria para melhorar o país" ou "votar é um dever de todos" (em 16,8\% das respostas). Também aqui, a imagem positiva das eleições é evidente. Ainda dentro desta tendência em participar, mas apresentando já algumas reticências, aparece o grupo dos que responderam "depende", enfatizando que votariam caso o candidato fosse bom $(14,2 \%)$. Por fim, afirmaram que votariam com certeza os entrevistados que participariam apenas porque gostam, porque acham interessante, porque se divertem votando $(4,7 \%)$.

Entre os que não votariam, encontram-se predominantemente aqueles que têm uma visão negativa da política, afirmando que os eleitores são enganados pelos políticos, que os interesses dos políticos não são os interesses do povo. Enquadramos também nesse caso as respostas do tipo "meu voto nada vale". Cabe observar que este grupo não é pequeno: foram 95 respostas, que correspondem a 13,9\% do total de entrevistados.

Provavelmente, também não votariam aqueles que nitidamente não se interessam pela política. Embora menos expressivo, este grupo reuniu 48 entrevistados (7\% do total), que fizeram afirmações tais como "se não aparecesse programa melhor, eu iria" ou "não me interesso por política".

\section{CONCLUSÃO}

A opção pelo voto facultativo prevaleceu amplamente, mas parece atingir de forma diferenciada os diversos segmentos sociais: as mulheres, mais que os homens, os jovens e idosos, mais que as pessoas de meia idade, as pessoas de baixa renda, mais que as de alta renda, os menos escolarizados, mais que os mais escolarizados, preferem menos o voto facultativo. Também os menos informados e alheios à política, em maior número apoiam o voto obrigatório. Este padrão apenas se modifica entre a parcela que possui preferência partidária ou participa de associações, pois nesse caso o percentual de apoio ao voto obrigatório é maior. Percebe-se, assim, que a preferência pelo voto obrigatório ou facultativo deve-se a questões de princípio, crescendo entre a população a idéia de que votar é um direito e não um dever. É interessante observar que mesmo aqueles que defendem a permanência do voto obrigatório o fazem predominantemente porque acreditam que, do contrário, poucos participariam. Não se trata, portanto, de valorizar a obrigatoriedade em si.

O percentual dos que votariam com certeza caso o voto se torne facultativo é pouco maior que $50 \%$ dos entrevistados; um número expressivo, 21,4\%, preferiu o intermediário "depende"; e 23,9\% disseram que não votariam. Na tentativa de caracterizar sociologicamente essas pessoas, poderíamos dizer que, embora apareçam diferenças percentuais entre os diferentes segmentos, são a escolaridade, em primeiro lugar, e a renda, em segundo lugar, as variáveis verdadeiramente significativas.

Como estudos clássicos de sociologia eleitoral já demonstraram, a não-participação encontra-se fundamentalmente relacionada à falta de informação. Esse dado torna-se mais nítido quando relacionamos a disposição em participar a outras variáveis. Por exemplo, a ideologia não aparece com grande relevância, pois tanto no que se refere às diferentes posições ideológico-societais, quanto às posturas relativas ao regime democrático, a maioria (em percentuais bastante próximos) afirmou que votaria. Nessas tabelas, destaca-se o grupo dos que não têm opinião, ou crêem que todos os regimes são iguais. Esses, em maioria, não votariam. Da mesma forma, entre os que não se interessam pela política, não assistindo aos noticiários, não debatendo com amigos e parentes, nem apoiando partidos e participando de associações, a tendência em participar cai significativamente.

Outro aspecto a ser observado é a tendência oposta à que vem sendo salientada até aqui. Se, por um lado, é verdadeiro que os mais pobres, mais despolitizados e mal informados provavelmente terão uma participação proporcionalmente menor se o voto se tornar facultativo, por outro, é verdadeiro também que a facultatividade do voto não eliminará os mais despolitizados e mal informados do processo eleitoral. E mais: como os dados referentes ao grau de lembrança das eleições passadas indicam, o grau de desinformação - principalmente sobre o Poder Legislativo - prevalece entre a população em geral. Isso significa que este problema diz respeito a questões que vão além da obrigatoriedade $\mathrm{x}$ facultatividade do voto. 
Finalmente, as justificativas apresentadas pelos entrevistados demonstram que o processo eleitoral vem sendo valorizado e positivamente encarado por uma parcela significativa da população. A esse percentual poderíamos somar os eleitores mais pragmáticos, que votariam se considerassem que o candidato valesse o custo. Entretanto, apesar desses indicadores positivos, não devemos minimizar as demonstrações de ressentimento contra o processo político, apresentadas por aqueles que não votariam. $\mathrm{Na}$ realidade, a pesquisa mostra que um percentual bastante alto de pessoas enquadra-se dentro de uma zona nebulosa, em que os valores democráticos estão muito distantes da consolidação.

\section{NOTAS}

* Este artigo apresenta os resultados da primeira etapa do projeto de pesquisa Obrigatoriedade do voto e determinantes sociais, que contou com a colaboração dos alunos bolsistas Alessandra M. Silva, Antônio M. Neto, Cássio R. E. Brito e Ivoney Mazzo, do Curso de Ciências Sociais da UEL; de Amaury de Souza, que prestou uma providencial assessoria telefônica; do Núcleo de Processamento de Dados da UEL, que tabulou os dados na fase inicial; da Assessoria Estatística do Departamento de Matemática Aplicada da UEL, principalmente Tiemi Matsuo, que nos orienta nas análises estatísticas. O projeto está sendo financiado pela UEL e pelo CNPq. Gostaríamos de registrar nossos agradecimentos a todos, frisando que os problemas que por ventura possam ter persistido são de nossa inteira responsabilidade.

1 A análise teórica e a interpretação dos dados serão apresentadas posteriormente.

2 As pesquisas dos últimos dez anos indicam um crescimento em favor do voto facultativo: em pesquisa de opinião realizada em 1988 nas capitais, $44 \%$ apoiaram o voto obrigatório, contra $53 \%$ que preferiram o voto facultativo; (CENTRO DE ESTUDOS DE OPINIÃO PÚBLICA, 1993) em pesquisa de 1989 entre as elites brasileiras, chegou-se a um percentual bastante próximo, de $43 \%$ favoráveis ao voto obrigatório e $45 \%$ favoráveis ao voto facultativo; (LAMOUNIER \& SOUZA, 1991, p.326) em 1991, outra pesquisa de opinião, entre as populações paulista e carioca, demonstra que apenas $29 \%$ eram favoráveis ao voto obrigatório e o crescimento para $69 \%$ de favoráveis ao voto facultativo. (TENDÊNCIAS, 1993) Esse dado foi confirmado nesta pesquisa no município de Londrina.

${ }^{3}$ O número de respostas não-sistematizáveis foi considerável. Estas, estão em Outras/NS/NR.

4 Segundo MOISÉS, (op. cit., p. 123, gráfico 5) em 1989, 59,2\% votariam e $37,8 \%$ não; nesse mesmo ano, alguns meses depois, $63,5 \%$ votariam, e $32,9 \%$ não; em $1993,49,9 \%$ votariam e $46,9 \%$ não.

5 A questão formulada foi aberta, para que o entrevistado desse espontaneamente sua opinião. A sistematização foi feita posteriormente, procurando-se respeitar o sentido da resposta. Mesmo assim, o número de respostas não-sistematizáveis foi considerável $(20,8 \%)$. Estas, estão em Outras/NS/NR.
OLIVEIRA, L. H. H. \& CARVALHO, M. N. T. de. Obrigatoriedade do voto e determinantes sociais. Londrina: UEL, 1998. Projeto de Pesquisa.

TENDÊNCIAS. Opinião Pública, n. 1, Campinas, jul./ago. 1993. Encarte de Dados de Opinião Pública.

\section{REFERÊNCIAS BIBLIOGRÁFICAS}

CENTRO DE ESTUDOS DE OPINIÃO PÚBLICA. Temas polêmicos da Constituinte, I. Campinas: Unicamp, 1993.

LAMOUNIER, B. \& SOUZA, A. Democracia e reforma institucional no Brasil: uma cultura política em mudança. Dados, v. 34, n. 3, 1991.

MOISÉS, J. A. Os brasileiros e a democracia (bases sócio-políticas da legitimidade democrática). São Paulo: Ática, 1995. 